\title{
IZKORISTEK GEOGRAFSKEGA PROSTORA TEROTORIALNE OBRAMBE DOLENJSKE POKRAJINE V VOJNI ZA SLOVENIJO V LETU 1991
}

\author{
Albin Gutman *
}

Izvleček:

UDK: 911:355.3/.4(497.4-11)

Geografski prostor je imel pomemben vpliv na bojno delovanje enot teritorialne obrambe $v$ vojni za Slovenijo leta 1991. Raznolikost površja Dolenjske, Bele Krajine in Posavja je $v$ bojnih aktivnostih pogosto omogočala prednost dobrim poznavalcem območja. Pripadniki Teritorialne obrambe so izkoristili poznavanje površja in prostorskih struktur sebi v prid. Onemogočili so večjo bojno aktivnost Jugoslovanske ljudske armade. Analiza spopadov pokaže dobro izbiro območij za boj s tehnično bolje opremljenim nasprotnikom.

Ključne besede: Geografski prostor, neodvisnost, boji, vojna, Teritorialna obramba, površje, vegetacija, ceste, vojaškogeografske smeri, Dolenjska, Bela krajina, Posavje

\begin{abstract}
:
Geographical space has had the most important impact on many engagements during the independent war in Slovenia in 1991. The units of territorial defence forces took advantage in positions because of good knowledge of terrain landforms. On military roots in the areas Dolenjska, Bela Krajina and Posavje region they used key terrain to defeat the enemy. Outcome of those actions was protection of Central Slovenia and withdrawal almost all combat units of Yugoslav Army.
\end{abstract}

Key words: geographical space, independent, war, key terrain, Territorial defence, landforms, vegetation, road, military route, Dolenjska, Bela krajina and Posavje region.

* General podpolkovnik, In.špektorat Republike Slovenije za obrambo, Ministrstvo za obrambo. Kardeljeva ploščad 25, Ljubljana. 


\section{UVOD}

V prispevku niso opisana celotna dogajanja v vojni za Slovenijo junija in julija 1991 na območju Pokrajinskega poveljstva Teritorialne obrambe (TO) Dolenjske. Izbrani so pomembnejši dogodki, ko je bil vpliv geografskega prostora prevladujoč. Enotam teritorialne obrambe je omogočal uspešnejše delovanje ali pa njihove aktivnosti izrazito omejeval. Dogajanja niso kronološko nanizana. Opisani so primeri, po območjih, ki so bila takrat v obrambni pristojnosti tedanjih občinah oziroma bojni odgovornosti območnih poveljstev TO. Avtor prispevka je v vojni za osamosvojitev Slovenije poveljeval celotni TO Dolenjske pokrajine.

Do leta 1990 so Teritorialno obrambo Dolenjske pokrajine sestavljali:

1. Pokrajinski štab TO Dolenjske z 52. brigado TO in prištabnimi enotami in

2. Občinski štabi TO občin Novega mesta, Metlike, Črnomlja in Trebnjega z enotami TO občin.

V mesecu oktobru 1990 je takratni Republiški štab Teritorialne obrambe Slovenije (RŠTO) začel pospešeno izvajati reorganizacija TO Slovenije. Zato se je precej spremenila organizacija in struktura TO Dolenjske pokrajine.

1. Oblikovan je bil Pokrajinski štab TO Dolenjske z brigado TO in prištabnimi enotami.

2. Območni štabi TO v Novem mestu, Črnomlju, Brežicah z enotami TO območnih poveljstev.

3. Priključeno je bilo območje kočevske in ribniške občine $\mathrm{z}$ območnim štabom TO v Ribnici z enotami.

Zato so bile enote TO Dolenjske tik pred vojno leta 1991 le deloma reorganizirane, hkrati pa so morale bojno nadzirati in obvladovati bistveno večje območje. Nedokončana reorganizacija bi lahko pomembneje vplivala na izid spopadov in vojne za osamosvojitev na Dolenjskem. Zaradi poznavanja območja in predvidevanja dejavnosti nasprotnika se to ni zgodilo. Enote To Dolenjske pokrajine so se uspešno zoperstavile močnejšemu nasprotniku in preprečile večje aktivnosti enot JLA tudi iz območja Hrvaške.

\section{POMEN OBMOČJA TO DOLENJSKE POKRAJINE ZA SLOVENIJO 1991 LETA}

\section{1. Meje in velikost območja}

TO Dolenjske pokrajine je v letu 1991 zajemala območja takratnih občin Brežice, Črnomelj, Kočevje, Krško, Metlika, Novo mesto, Ribnica, Sevnica in Trebnje. Sestava je bila precej pestra, saj so štabi in enote TO pred združitvijo pripadale pokrajinskim štabom TO s sedeži v Novem mestu, Brežicah in Ljubljani. Naziv Teritorialna obramba Dolenjske pokrajine označuje del organizacijske strukture takratne TO Slovenije. TO Dolenjske torej ne označuje neke zaključene geografske celote, temveč organizacijsko celoto poimenovano po njeni največji sestavini. Po naravnogeografski regionalizaciji (Gams, 1996, priloga - zemljevid) je zajemalo del Kočevsko-Ribniškega hribovja; Kočevsko-Ribniško dolino; slovenski del Gornje kolpske doline s Čabranko; del Suhe krajine in Dolenjskega podolja; 
Mirnsko dolino in del Senovskega podolja; Novomeško pokrajino in Krško kotlino; del Bizeljskega; slovenski del Gorjancev in Belo krajino.

Območje pokrajine je mejilo z Hrvaško - najdaljša meja (na jugu in jugovzhodu), na TO Notranjske (na zahodu), TO Ljubljanske pokrajine (na severozahodu) in TO Zahodne Štajerske (na severovzhodu).

\section{2. Vojaškogeografski pomen območja pred vojno leta 1991}

Čez območje odgovornosti pokrajinskega štaba TO Dolenjske so vodile v osrednjo Slovenijo pomembne vojaško geografske smeri ${ }^{1}$ :

* Dolenjska smer, ki se ji Krški kotlini priključi

* Posavska smer in

* Kočevska smer.

Vse smeri so imele izreden operativen in taktičen pomen za JLA, Za nastajajočo samostojno Republiko Slovenijo pa so predstavljale strateško smer proti Ljubljanski kotlini in glavnemu mestu. Zaradi bližine strateško pomembnega območja Zagrebške kotline v trikotniku: Zagreb-Sisak-Karlovac (Bratun, 1997, 168), je bilo na območju odgovornosti TO Dolenjske pokrajine večje število vojašnic, skladišč in vadišč tedanje JLA.

Razporejene so bile na večjih lokacijah v občinah Novo mesto, (vojašnica Bršljin), Trebnje (skladišče Mokronog), Črnomelj (vojašnica in skladišča pri Otovcu), Ribnica (vojašnica) in Brežice (vojaško letališče Cerklje na Dolenjskem).

Večje število za boj pripravljenih in usposobljenih enot JLA je bil razmeščen tik za mejo z Hrvaško v Zagrebu (poveljstvo 5. Vojaškega območja), Samoboru in Jastrebarskem (oklepne enote) in v Karlovcu (vojaška akademija, protiletalske enote in inženirija).

Dodatni pomen so predstavljali komunikacijski snopi med poveljstvom 5. vojaškega območja $v$ Zagrebu in poveljstvom korpusa $v$ Ljubljani, ki so potekali čez območje Dolenjske pokrajine. Zato je bilo na območju TO Dolenjske večje število enot JLA, kot v nekaterih drugih predelih Slovenije.

\section{VOJAŠKOGEOGRAFSKI POMEN OBMOČJA V VOJNI LETA 1991}

Ko je poveljnik Pokrajinskega štaba TO Dolenjske, na enem takrat številnih, sestankov pri načelniku Republiškega štaba za TO Slovenije, opozoril na verjetno možnost delovanja enot JLA na smereh, ki že stoletja vodijo čez Belo Krajino na Dolenjsko, so ga kolegi prijazno podučili, da se zgodovina vedno ne ponavlja, da tako kot je nekoč bilo, ne bo nikoli več, zato naj ga zgodovina in geografija preveč ne skrbita.

\section{1. Izkoristek prostora $\mathrm{v}$ Beli krajini}

V letu 1991 je bilo ozemlje Bele krajine razdeljeno med občini Črnomelj $\left(488,04 \mathrm{~km}^{2}\right)$ in Metlika $\left(108,37 \mathrm{~km}^{2}\right)$. Najpomembnejša kraja v Beli krajini sta Črnomelj, kjer je bil v vojni za Slovenijo sedež območnega poveljstva TO ter Metlika, ki je z nastankom države Slovenije postala obmejno mesto z Hrvaško. Osnovne geografske poteze območja,

I Primerjaj: Bratun, Z., 1998: Geografski dejanniki državnovamostnega sistema. Doktorska disertacija. Oddelek za geografijo, Filozofska fakulteta. Univera vi Ljubljani, Ljubljana. Str: 225 - 2.37. 
pomembne za vojaško vrednotenje sestavljajo: belokrajnski ravnik; robne dinarske planote in prevali proti Novomeški pokrajini; Kolpa, Lahinja in Krupa.

$\mathrm{Z}$ vrtačami in majhnimi vzpetinami razgiban belokrajnski ravnik, ki zajema osrednji del občine Črnomelj, je ugreznjen na tektonskih prelomnicah med Gorjance, Roško planoto, Poljansko goro ter reko Kolpo na jugu. Na skrajnem vzhodnem delu Bele krajine, v občini Metlika, prehaja $v$ nizek terasast svet ob Kolpi, ki se na severnem delu zaključuje na pobočjih Gorjancev. Ob tektonski prelomnici, so nastala strma pobočja, znatno višja od ravnika, ki otežujejo prehode proti Dolenjski in na Kočevsko. Najznačilnejši prehodi vodijo čez Vahto $(635 \mathrm{~m} \mathrm{n}$. v.), prek strmega prehoda $(470 \mathrm{~m} \mathrm{n}$. v.) po pobočju Semeniča v odročno Rožendolsko dolino in čez preval Brezovico (547 m n. v.) v Črmošnjiško Poljansko dolino in na Kočevsko.

\section{Primer premika enote zračne obrambe JLA čez preval Vahta}

In ravno prehod prek Kolpe pri Metliki si je za svojo pot izbrala večja enota zračne obrambe iz Karlovca, ki je med prvimi delovala v sklopu napada na državo Slovenijo pod pretvezo zavarovanja mejnih prehodov SFRJ. Sporočilo o njenem premiku in ukaz za delovanje enot TO smo dobili prepozno. Tako za njeno ustavitev ni bilo mogoče izkoristiti skoraj idealne pogoje na območju Gorjancev v bližini prevala Vahta. Ni bilo mogoče pravočasno pripraviti zasede na načrtovanih lokacijah vzdolž ceste Suhor - Težka voda, ki vijugasto sledi pobočju in prevalu. Na celotni dolžini so na več mestih primerni naravni pogoji za učinkovito zaustavitev in napad na enote $v$ premiku. Po prehodu enote smo v naslednjih dneh vojne postavili močne ovire na tej komunikaciji, ki je postala za nekaj dni popolnoma neprehodna za ves promet. Zato enote JLA iz Karlovške kotline niso kasneje mogle učinkoviteje posegati na smeri proti Novemu mestu.

\section{Primer vojašnice Črnomelj in skladišča Vražji kamen}

V Črnomlju in njegovi okolici so bili razporejeni različni objekti JLA. Enote TO so svoje delovanje usmerile proti najpomembnejšim, predvsem proti tistim, ki so zaradi lege nudili možnost uspeha TO.

Večji vojaški problem je predstavljala vojašnica v Črnomlju. Od preostalega mesta jo je ločevala Lahinja. Njena lega je omogočala izvedbo učinkovite blokade in nadzora nad dogajanji v vojašnici. Na vseh pomembnejših dostopih v mesto so bile postavljene ovire, ki jih ni bilo mogoče obiti. Čeprav je posadka vse objekte znotraj vojašnice utrdila in pripravila za dolgotrajni boj, ni ves čas vojne niti enkrat uspela posredovati zunaj vojašnice in tako ni mogla pomagati posadkam v objektih izven vojašnice, kar je bilo odločilno za izvajanje aktivnosti enot TO pri Vražjem kamnu.

Objekti skladišč v Otovcu neposredno ob želežniški progi Novo mesto - Metlika so bili za obrambo povsem neprimerni. Skladišče v gozdu severno od Črnomlja, poimenovano po 172 m visokem Vražjem kamnu, je zaradi lege neposredno ob komunikaciji omogočalo neoviran in prikrit dostopa. Zaradi učinkovite blokade vojašnice, je predstavljalo možnost za aktivno delovanje enot TO brez prevelikega tveganja. Po odločnem ukrepanja enot TO se je posadka predala brez boja. 


\section{2. Izkoristek prostora na območju občine Novo mesto}

Občina Novo mesto $\left(758,92 \mathrm{~km}^{2}\right)$ je obsegala jugovzhodni del Dolenjske z Novomeško kotlino z obrobnim hribovitim svetom med Raduljo, Gorjanci in Kočevskim Rogom ter glavnino Suhe krajine. Osnovne geografske poteze območja, pomembne za vojaško vrednotenje.

Osrednjo lego ima Novomeška kotlina z reko Krko. Ob njej potekata dve prelomnici. Ena z dinarsko smerjo ob robu Kočevskega Roga in druga od Soteske ob Krki mimo Straže ter ob Trški gori in Vinjem vrhu, torej skoraj pravokotno na prvo. Zahodni del Novomeške kotline obsega Prečno z letališčem in Topliško dolino, kjer poteka cestna povezava prek Črmošnjic v Belo krajino in na Kočevsko. Na desnem bregu Krke se proti Gorjancem z najvišjim vrhom Trdinov vrh (1181 m n. v.) postopno dviguje Podgorje s terasami in rebrastimi slemeni. Gorjanci so široko pogorje z alpsko slemenitvijo, vendar z dinarsko strukturo. Na višjih predelih je svet močno zakrasel in pogozden, na nižjih predelih, ki se spuščajo vse do reke Krke, pa so številna naselja. Na jugozahodni strani Novomeške kotline se razprostira Roško višavje z najvišjim vrhom Veliki rog (1099 m n. v.). To je obširen, po večini gozdnat, planotast svet s slemeni dinarske smeri in posut s številnimi vrtačami. Na vzhodu prehaja Novomeška pokrajina v Krško kotlino.

In prav od tam je pretila velika nevarnost posredovanja enot JLA. V Novem mestu je bil sedež pokrajinskega in območnega štaba TO. V okolici mesta so bila mobilizacijska zbirališča najmočnejših enot TO. Največji objekt JLA je bila vojašnica na obrobju mesta $v$ neposredni bližini industrijskega kompleksa. Več objektov, predvsem skladišč, je bilo v neposredni bližini mesta, kar je oviralo blokado in nadzor, saj je med objekti potekal občasen, sicer nadzorovan, promet po stranskih poteh.

\section{Primer Poganci}

Poganci so majhno naselje pred vstopom v Novo mesto ob cesti, ki vodi iz Bele krajine preko Gorjancev v Novo mesto. Na vzhodni strani ceste teče potok Težka voda, ob katerem se razprostira ravninski svet, ki se nadaljuje v nekaj sto metrov oddaljeni Gotenski boršt. Na zahodni strani ceste se začenjajo pobočja Poganškega vrha (242 m n. v.). Po ukazu RŠTO je bila za zaustavitev kolone postavljena nenasilna blokada ob opuščenem kamnolomu, kjer se cesta začne vzpenjati v desni ovinek proti Novemu mestu. Tam smo kolono ustavili. Enota TO pa je zaprla pot v smeri Gorjancev. Cesta od Pogancev proti zahodu ob potoku Petelinec, ki smo jo pustili neovirano, je vodila mimo skladišč JLA, vendar se kolona ni hotela premakniti v tej smeri, saj je $v$ gozd speljana makadamska cesta, vzdolž katere bi bil mogoč uspešen napad na kolono. Za poveljujočega oficirja je predstavljala nepoznano območje in s tem povezano večje tveganje.

V času zaustavitve kolone so se začele sovražnosti po celi državi. Položaj, ki je bil primeren za zaustavitev in blokado kolone, ni bil primeren za napad, saj od zahteve po nenasilni blokadi ni bil mogoč enostaven prehod $v$ boj. Kolona je hotela nadaljevati pot proti Ljubljani, čeprav bi bilo za nas ugodnejše, če bi hotela v Cerklje.

\section{3. Izkoristek prostora na območju občine Trebnje}

Osrednji del Dolenjske zavzema občina Trebnje $\left(308 \mathrm{~km}^{2}\right)$, ki vključuje tri dokaj zaključena območja. Mirnsko dolino,ki na jugu prehaja v Krško hribovje, Temeniško dolino $s$ in Dobrniško kotlino. Relief je normalen in kraški. Stikata se ob Temenici zahodno od Trebnjega. Površje je razgibano, pretežno gričevnato, vendar lažje prehodno. Območje deli hitra cesta Obrežje Ljubljana, ki med Plusko in Bičem poteka po klancu Medvedjek. 


\section{Primer Medvedjek}

Cesta, ki je v tem delu razširjena v tri vozne pasove je speljana v daljši levi ovinek, ki ga oblikuje raztegnjen klanec na pobočju Medvedjeka. Vzporedno poteka v neposredni bližini lokalna cesta. Vmes je skoraj v celoti gozd in grmičje, kar ovira neposreden pogled na hitro cesto. Vzdolž ceste se proti severu dviga gozdno območje Medvedjeka z Videm vrhom (387 m n. v.), proti jugozahodu pa pobočje pada v travnati dol, ki se na drugi strani nadaljuje v nepregledno gozdno območje. Na travnatih delih pobočja je nekaj domačij, v tistem času je bila tam nameščena tudi raketna postaja proti toči. To območje so kasneje letala JLA raketirala. Položaji za zasedo so bili izbrani na Medvedjeku severno nad cesto, torej višje od blokirane kolone, ter ob vznožju klanca v bližini naselja Korenitka, torej nižje od kolone. Omogočali so delovanje in izmik enot. Klanec Medvedjek je bil izbran iz več razlogov. Bil je dovolj oddaljen od začetnega kraja blokade, da smo ob upočasnitvi kolone po hitri cesti Novo mesto- Ljubljana lahko pravočasno v zasedo premaknili enote TO Izkušnja iz Pogancev je bila, da je težko braniti na hitro postavljene ovire. Vse enote JLA, ki bi hotele posredovati iz vojašnic, bi bilo možno pravočasno zaznati in onemogočiti njihove premike v proti Medvedjeku. Primernejše je bilo tudi zaradi razpršene poseljenosti.

Po letalskem napadu in vztrajanju kolone na klancu Medvedjek, so bile postavljene ovire na vse možne izhode iz hitre ceste in organizirana obramba na ključnih objektih na smeri Novo mesto - Karlovac in Trebnje - Mokronog - Sevnica. Odprto smo pustili le pot do postavljene blokade v Krakovskem gozdu.

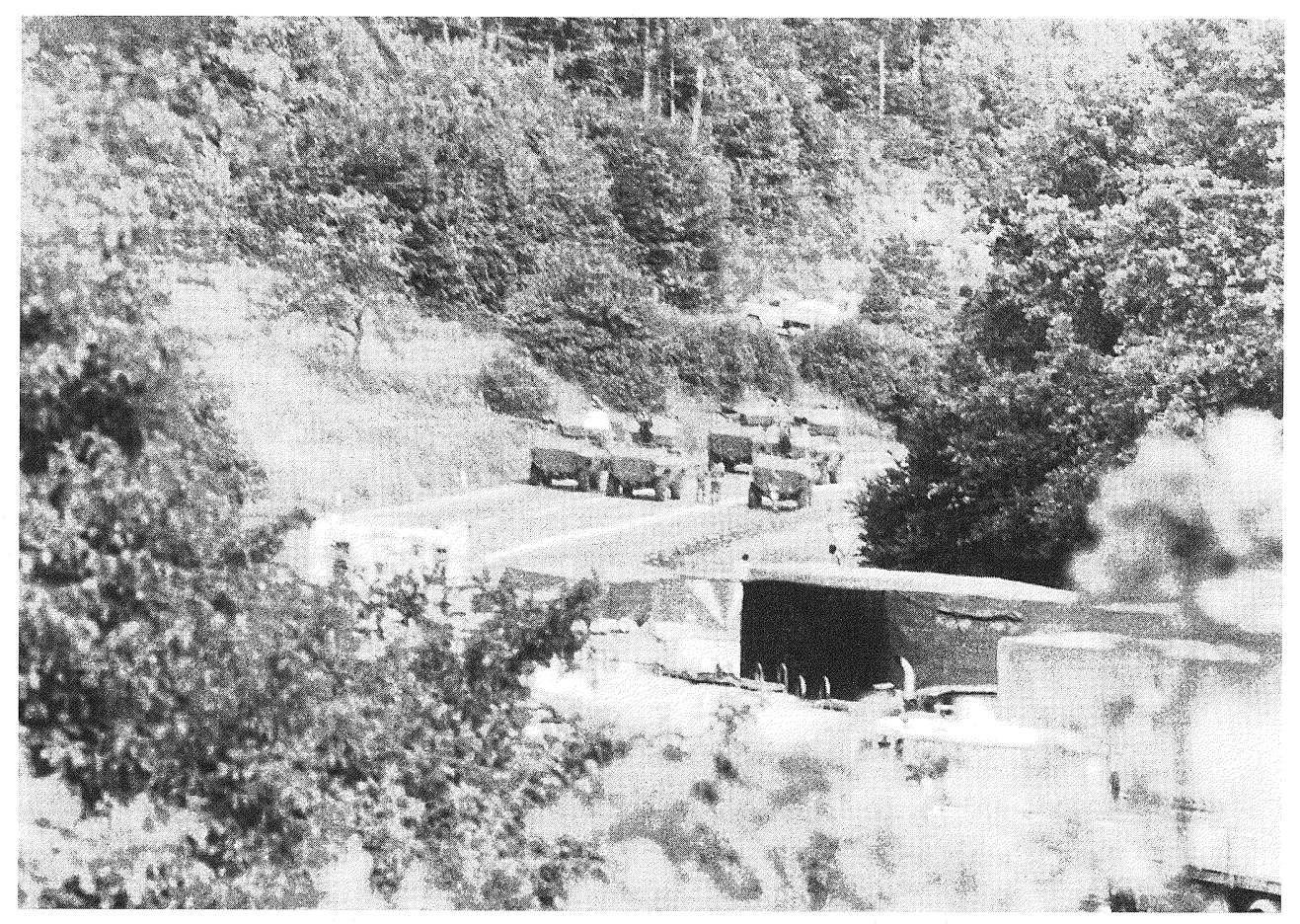

Slika 1: Klanec Medvedjek, junij 1991, Foto: Tomaž Bukovec 


\section{4. Izkoristek prostora na območju Posavja}

V letu 1991 so Posavje sestavljale občine Sevnica, Krško in Brežice.

Občina Sevnica $\left(292,62 \mathrm{~km}^{2}\right) \mathrm{z}$ občinskim središčem v Sevnici je zajemala del Posavja in del Posavskega hribovja. Na njenem območju ni bilo objektov in enot JLA. TO pa je imela manjše sile za nadzor in blokado komunikacij.

Občina Krško $\left(345,14 \mathrm{~km}^{2}\right)$ je zajemala na severu Posavsko hribovje in jugozahodno od Save Krško hribovje in obrobje Novomeške pokrajine, na jugu sleme Gorjancev ter Krško kotlino, ki obsega Krško polje, Krakovski gozd ter Kostanjeviško dolino, ki sega čez Krko proti zahodu vse do Gorjancev. V občini ni bilo enot JLA. TO so sestavljale enote prostorne strukture, ki so bile v vojni uporabljene že prvi dan.

Občina Brežice $\left(267,65 \mathrm{~km}^{2}\right)$ obsega Brežiško ravan, Bizeljsko, pas Posavskega hribovja in vzhodni del Krškega polja, med Savo in Krko ter Krakovskim gozdom. V Brežicah je bil sedež območnega štaba TO, ki je poveljeval enotam TO v Posavju. Za JLA je bilo najpomembnejši letališče v Cerkljah.

Bojno delovanje enot TO je, s premikom oklepne kolone na območje Krakovskega gozda, dobilo povsem nove razsežnosti. TO Dolenjske pokrajine je prevzela pobudo.

\section{Primer Krakovski gozd}

Krakovski gozd je močvirno območje, prepleteno s številnimi kanali za odvajanje vode. Precej gost dobov gozd je zaraščen $z$ grmovjem in močvirnim rastlinjem. Območje je neprehodno za vozila, v večjem delu leta pa je prehod nemogoč tudi peš. Orientacija znotraj gozda je zelo težavna. Hitra cesta, ki prereže gozd je zgrajena na nasipu. Na njej je bila postavljena ovira iz tovornih vozil, okrepljena $z$ minskimi sredstvi in branjena $z$ enoto TO. Nekaj kilometrov proti Novemu mestu je druga enota TO preprečevala vrnitev oklepni koloni JLA, ki se je premaknila iz Medvedjeka, proti Ljubljani. Gozd s podrastjem pa sega vse do ceste, vzdolž katere na njeni vzhodni strani poteka plinovod. Preglednost s ceste je majhna. Zato je povsem razumljivo, da je poveljnik enote JLA svojim nadrejenim poročal. da je nekje med Brě̌icami in Zagrebom! Nasip, ki se dviga ob cesti nad pogozdeno okolico je deloma zmanjšal možnost streljanja protiletalskih topov. Gosti gozd pa je pripadnike TO varoval pred opazovanjem, saj posadke v vozilih niso mogle učinkovito spremljati aktivnosti enote TO. Nudil je tudi delno zaščito pred ognjem iz pehotnega orožja in protiletalskih topov, ki so v pehotnem boju uničujoče orǒ̌je. Območje je nenaseljeno in zato tudi letalski napad, pred katerim so se enote TO, po izvedenem uspešnem napadu na kolono, pravočasno umaknile, ni povzročil y̆rtev med civilnim prebivalstvom, kot se je to dogodilo na Medvedjeku.

\section{Primer Cerklje}

Letališče Cerklje, ki je edino povsem vojaško letališ̌̌e v Sloveniji, lě̆i pod obronki Gorjancev v Krško Brě̌iški kotlini. Okoli letališča so kmetijske površine, razen manjšcga pogozdenega dela na severni strani. Celoten kompleks letališ̌̆a (59) hal) je nemogoče v celoti blokirati bre\% večjih sil, ki pa jih v letu 1991 nismo imeli. Letališč Cerklje torej ni bilo mogočc blokirati po enakem principu kot ostale vojašnice JLA na območju TO Dolenjske, kjer so bile postavljene ovire na vsch dostopih do vojašnic, določene sile za obrambo in kontrolo območij med ovirami. Na ta način smo povsem usmerili premike enot JL A, celotno območje pa lăje nadzorovali. 
Dostop do letališča je možen z vseh strani in brez posebnih težav je mogoče vse dostope tudi nadzorovati. Zato je bilo načrtovano in izvedeno oviranje stran od letališkega kompleksa. Blokiran je bil možen izhod iz Krško - Brežiške doline. Ovire smo postavili v Krakovskem gozdu, na cesti Cerklje - Kostanjevica, na mostovih čez Savo v Krškem, na cesti Krško - Sevnica in še na nekaterih pomembnejših lokalnih cestah. Kljub maloštevilnim silam TO, je bila blokada letališča ves čas vojne, kljub posadki okrepljeni z bataljonom padalcev uspešna. Zaradi dobre preglednosti nad kompleksom letališča in njegove velikosti ni bilo mogoče delovati po ciljih na letališču brez velike nevarnosti za enote TO. Zato je bil izveden le ognjeni udar z minometi z območja vasi Velike Malence, ki ni povzročil večje škode. Imel pa je velik psihološki učinek, ker so po napadu vsa letala zapustila letališče!

\section{Primer Prilipe}

Hitra cesta od Brežic proti Zagrebu poteka ob vznožju vzhodnega dela Gorjancev deloma po nasipu neposredno ob reki Savi. Vzporedno s hitro cesto poteka asfaltna cesta od Čateža do Prilip. Cesta je vrezana v strmo pobočje, ki se spušča proti Savi. Ovire so bile postavljene na najožjem delu, pri vhodu v Čateško polje. Na pobočju nad Slovensko vasjo je bila postavljena opazovalnica. Z nje so pripadniki TO nadzirali celotno območje proti Zagrebu in Samoborju. Lokacija ovir in položaji enote so bili izbrani tako, da so bile izkoriščene vse naravne danosti terena. Ovire so bile postavljene na mostu čez Krko na hitri cesti Zagreb - Ljubljana in so kljub letalskem napadu še naprej onemogočale prehod oklepni koloni JLA, ki je iz smeri Zagreba hitela na pomoč razbiti enoti v Krakovskem gozdu. Edino preostalo pot je predstavljala lokalna cesta Prilipe - Čatež, nad katero je enota TO pripravila zasedo.

Položaji enote TO so bili na robu terase, nad komunikacijo, po kateri je bil pričakovan prihod nasprotnika. Položaj je omogočal varen izmik enote. Kanalizirana smer je prisilila oklepno enoto, da je nastopala v kolonskem razporedu. $\mathrm{S}$ tem je bila bistveno zmanjšana učinkovitost in ognjena moč enote. Tako je enota TO lahko izvajala boj s posamičnim oklepnim vozilom, ki je po uničenju postal dodatna ovira. Po uničenju čelnih oklepnih vozil je bila oklepna kolona zaustavljena in se je še isti dan vrnila proti Zagrebu.

\section{5. Izkoristek prostora na območju občin Ribnica in Kočevje}

Del Dolenjske, južno od Velikolaščanske pokrajine pripada Ribniško-Kočevski dolini in Ribniško-kočevskemu gorovju. Z malo izjemami je to dinarski kraški svet. Pokrajina obsega razgiban in planotast kraški svet z dinarsko slemenitvijo. Osrednji del Kočevskega je pripadal občini Kočevje $\left(765,86 \mathrm{~km}^{2}\right)$. Občina Ribnica $\left(255,94 \mathrm{~km}^{2}\right) \mathrm{z}$ osrednjo Ribniško dolino, sredi katere leži Ribnica. Poselitev je zgoščena v Kočevju in Ribnici h katerima gravitirajo okoliške vasi in zaselki. Komunikacije potekajo v smeri proti Ljubljani, Novem mestu, Črnomlju in Postojni. Za celotno območje je značilna velika gozdnatost. Gozd, razen na območjih kraških polj, sega povsem do komunikacij.

Območje je predstavljalo tudi mejo TO Dolenjske pokrajine proti zahodu in severu. $\mathrm{V}$ Ribnici je bil sedež območnega štaba teritorialne obrambe, ki je poveljeval enotam TO na območju občin Ribnica in Kočevje. V Kočevski Reki je bilo poveljstvo enote, ki jo danes najbolj poznamo pod nazivom 1. specialna brigada MORiS, ki pa je naloge izvajala povsod po Sloveniji. 


\section{Primer vojašnice v Ribnici}

V Ribnici je bila nameščena artilerijska enota JLA, ki je $z$ objekti na robu naselja ob potoku Sajevec in presekanim odprtim prostorom proti jugozahodu, predstavljala neugoden objekt za izvajanje bojnih delovanj. Zato direktni napad na vojašnico ni bil načrtovan. V primeru spopadov ne bi bilo mogoče omejiti spopad le na objekte vojašnice in zavarovati celoto naselje in njegovo okolico pred učinki orožij enote JLA. Težavnost delovanja enot TO so dopolnjevale tudi nenehne zahteve vodstva občine Ribnica, da se je spopadu med TO in JLA potrebno izogniti za vsako ceno. Vojašnico je bilo mogoče, glede na dostope do objektov, učinkovito blokirati, kar je povsem izničilo njeno veliko ognjeno moč in številčno posadko prisililo na čakanje. Vse aktivnosti znotraj vojašnice smo nadzirali. Nenehno pozivanje na prestop v TO je slabilo bojno moč enote. Enota JLA z artilerijskimi orožji ni mogla zapustiti vojašnice. Prostor znotraj vojašnice ni dovoljeval razporeditve večjega števila artilerijskih orožij za učinkovito obstreljevanje enot TO. Zato so le iz nekaj topov, ki so jih lahko postavili v bojni položaj znotraj vojašnice, izstrelili več granat proti Kočevski Reki, ki pa na pogozdenem zemljišču našim enotam niso povzročile nobene škode.

\section{ZAKLJUČEK}

Čez območje odgovornosti Pokrajinskega poveljstva teritorialne obrambe za Dolenjsko vodijo pomembne vojaškogeografske smeri. Na ključnih Poselitev je zgoščena v Kočevju in Ribnici h katerima gravitirajo okoliške vasi in zaselki. Komunikacije potekajo v smeri proti Ljubljani, Novem mestu, Črnomlju in Postojni. Za celotno območje je značilna velika gozdnatost. Gozd, razen na območjih kraških polj, sega povsem do komunikacij. lokacijah so bile razporejene po vojašnicah in drugih objektih enote takratne JLA. Umestitev vojašnic v urbana okolja je omejevala možnosti za izvajanje spopadov, saj bi uporaba orožij ogrožala tudi civilno prebivalstvo. Težišče spopadov smo prenesli izven večjih naselij, vendar je policentrična poselitev dodatno zmanjševala izbiro ugodnih lokacij. Možnosti, ki jih je nudilo posamezno geografsko okolje so enote uspešno uporabljale in deloma zmanjševala prednost JLA $v$ bojni tehniki, zlasti v oklepnikih in letalstvu.

\section{LITERATURA:}

1. Bratun, Z., 1998: Geografski dejavniki državnovarnostnega sistema, Doktorska disertacija, Oddelek za geografijo, Filozofska fakulteta, Univerza v Ljubljani, Ljubljana.

2. Gams, I., Geografske značilnosti Slovenije, Mladinska knjiga, Ljubljana.

3. Gutman, A., 1991: Osebni zapiski, Dnevnik, Novo mesto.

4. Krajevni leksikon Slovenije, 1976: II. in III. knjiga, DSZ, Ljubljana. 